\title{
Commentaries on Serials Publishing
}

\section{Ronald F. Dow, Karen Hunter, and G. Gregory Lozier}

\begin{abstract}
This article is the last in CERL's series on scholarly communications and serials prices. The previous articles in the series are "Longitudinal Study of Scientific Journal Prices in a Research Library," by Kenneth E. Marks, Steven P. Nielsen, H. Craig Petersen, and Peter E. Wagner (March 1991); "Resolving the Acquisitions Dilemma: Into the Electronic Information Environment," by Eldred Smith (May 1991); "Serials Pricing and the Role of the Electronic Journal," by Paul Metz and Paul M. Gherman (July 1991); and "Without Feathers: Effects of Copyright and Ownership on Scholarly Publishing," by Ann Okerson (September 1991).
\end{abstract}

\section{THE SERIALS PRICING DILEMMA}

This series of articles, published over the past eight months by College $\& R e$ search Libraries, paints an exasperating picture of a serials pricing crisis that has been and will continue to affect research libraries for some time. Issues that are at the heart of the problem are not about to dissipate. For example, recent actions demonstrate that commercial publishers are continuing to combine and, through combination, secure even more leverage in the scholarly communication process. We need only witness the recent purchase of Pergamon Press PLC by Elsevier, or read of Elsevier's continuing expectations for profit increases of 15 to 20 percent annually-achievable through acquisition and by expanding its list of scholarly scientific publications, ${ }^{1}$ or receive the "good news" from Elsevier that this year's serial price increases are being absorbed by a stronger exchange rate, ${ }^{2}$ to know that there is no good news to report.
For librarians, serials price increases represent a problem without precedent, for this is not a crisis of our own making. Yet if we receive no help from our partners in the scholarly communication process, the crisis can lead to our unmaking. Traditional library crises involve space, money to build new collections, automation initiatives, and the like. When library space is the issue, a new building resolves the problem and brings to campus an impressive structure that can be pointed to with pride by students, faculty, and administrators as a visible commitment by the college or university to the learning process.

Many a library director has made the case, with strong faculty support, for growing collection budgets. Growth represents tangible evidence of an institution's research strength as collection size and acquisitions budgets are nationally touted. And institutional investments in library automation have expanded access to materials from home

Ronald F. Dow is Assistant Dean of Planning and Administrative Services, The Pennsylvania State University Libraries, University Park; Pennsylvania 16802; Karen Hunter is Vice President and Assistant to the Chairman, Elsevier Science Publishers B.V., New York, New York 10010; and G. Gregory Lozier is Executive Director of Planning and Analysis, Affiliate Associate Professor of Education, and Research Associate, Center for the Study of Higher Education, The Pennsylvania State University, University Park, Pennsylvania 16802. 
or office, linked campuses to national utilities whose databases afford access to resources far beyond the universe of materials available locally to patrons, and improved management of libraries' administrative tasks, such as circulation and checkout. Each of these instances represents a significant problem met and faced at one time or another by the library community. In case after case, using faculty and student support, libraries have compiled evidence that institutional investments in each of these undertakings would result in a tangible and evident value, worthy of the financial resources spent.

Unfortunately, the serials crisis has not stopped faculty from placing articles with overseas publishers - the very publishers at which librarians are railing. Also, faculty have demonstrated no elasticity of demand for access to the publications that are the source of libraries' problems, giving librarians little latitude for developing leverage with publishers by threatening cancellation of subscriptions as prices rise. Meanwhile, academic administrators quickly are losing their ability to support escalating materials budgets and are showing little sign of supporting librarians as they grapple with cancellations that will inflame faculty and librarians alike. Librarians ask for more and more of each institution's resources to maintain serials collections at current levels-spending that cannot be pointed to easily as a new program initiative. Because university financial resources are limited, because little tangible value added accrues for the investment, and because there is little likelihood that either commercial publishers or the academic reward system will change soon, librarians are being left to deal with a crisis of unprecedented circumstances.

So, then, how should someone who is participating in the administration of a large research library respond to the concerns posed by this series of articles and to the serials crisis in general? It seems to me that many of the management strategies for these difficult times fail to resolve the problem or to buy libraries either enough time or additional resources to survive the crisis intact. Calls for cooperative solutions with our partners in the communications process have proven ineffectual. That leaves us with a few strategies only vaguely hinted at in this series, strategies that attempt to acquire some control over the process until better alternatives develop. Examples of these stratagems include passing the cost of serials increases through to funding sources with pockets deeper than those of our parent institutions; altering the scholarly communication process by indirect means; or, through cooperative library ventures, attempting to change directly the marketplace in which commercial publishers of scholarly literature compete.

To illustrate, let us first look at one strategy that seeks to pass through the costs of materials increases to another funding source. Remember that a substantial proportion of what is published in the scholarly scientific literature is the result of funded investigation. Much has been written in recent months concerning indirect overhead costs in support of this research. Clearly, library charges are an appropriate component for cost recovery. Yet virtually no libraries factor in the total cost of literature that supports research or the escalating costs to maintain these collections. The U.S. government allows libraries to recover costs for those items that can be shown to support research, above and beyond instruction or faculty continuing education. The government requires a method of accounting for these costs that is both reasonable and capable of being replicated for verification. It would seem quite defensible to declare all serial literature with some identifiable percentage of articles sponsored by research dollars as literature purchased solely in support of research.

For example, a library might argue that any journal where, say, 30 percent of the published articles in one or two issues of the serial report on the results of funded research-as identified by author acknowledgment in the introduction or text of the work - should be labelled as research literature. The library can argue 
that these publications are purchased primarily to inform faculty and students of research results-because this is how scientists have chosen to disseminate the outcome of their work-and to stimulate similar activity, leading to future funding opportunities. If these publications were not purchased by the library, information concerning this research would not be disseminated and new proposals would not be forthcoming. Furthermore, because funding agencies allow scholars to pass copyright to publishers, providing no other means of disseminating research results, libraries have little choice but to subscribe to this literature. Therefore, the total costs of all journals wherein $20,30,40$, or some other percent of the articles are funded by research dollars should be declared for research support exclusively and be fully cost recoverable on an annual basis through overhead charges. This accounting method is fully capable of replication and places the financial responsibility for funding these subscriptions on agencies who are responsible for the context of the publications and whose pockets are deeper than the library's.

This leads to a second strategy for combating the serials crisis. Should these agencies be faced with the annual escalation of costs to support serials collections, they might well develop new mechanisms for disseminating the results of the research they fund. By disallowing the transfer of copyright on articles that are a direct result of funded research, these agencies might hasten the spread of the electronic journal, encourage the creation of online NTIS dissemination devices, or even curtail the volume of literature that reports on only some portion of the research product, resulting in follow-up articles and an expanding publication list. In short, by passing on the cost of these serials, librarians may be able to affect indirectly the scholarly communications process in a manner that could not be achieved by direct action.

Conversely, perhaps direct action is called for. Serials publication is one activity that requires little or no working or start-up capital. Perhaps libraries, in consort with parent institutions, state development agencies, and a few sympathetic funding sources, could enter the publishing marketplace. Why not buy out the editorial boards of several of the significant and more costly scientific serials, work with these boards, and contract printers, to develop alternatives to the original publications-new publications whose reputations would reside in the credibility of the editorial boards? Then, by agreement between research libraries, we would cancel subscriptions to the original publications en masse. This strategy, if implemented in a selective fashion by a group of research libraries and their sponsoring organizations, could serve as a pilot project for alternatives to scholarly publishing without upsetting the existing academic reward structure, could bring competition to the marketplace, and could begin to define profit margins to the advantage of consuming institutions in a way that counters the prevailing trend of corporate concentration. If done properly, it also could serve as a mechanism to aid in building links between universities and local economic development concerns.

Obviously, new approaches must be attempted to resolve what has become the librarian's dilemma. Faculty may be sympathetic to the issue, but tradition and the faculty reward structure mitigate against their full support. There is a limit to what campus administrators are willing to expend or are capable of expending to resolve this crisis, and there is a limit to their resolve to stand behind librarians who are being forced into making serials cuts to meet financial constraints. Clearly, it is easier to challenge librarians to resolve the serials issue than to support change in the scholarly communications process, which is at the heart of this dilemma. Campus administrative positions turn over too quickly for librarians to expect long-term institutional leadership in the resolution of what has become our plight.-Ronald F. Dow

\section{CUSTER'S LAST STAND?}

General George Custer gained his place in history the stupid way. His arrogance and strategic misjudgments cost 
him his life and the lives of his troops, while they provided a moral victory for the Indians. There are many in the library community who would identify with the Indians and hope to recreate Little Big Horn, with commercial journals publishers in the role of the military. In fact, they want the Indians to win not just the battle, but the war. On seemingly all fronts-whether with statistical analyses, faculty lobbying, copyright (re)interpretations, new electronic journal start-ups, or visions of universityowned, library-run local or national archives-the call for change is loud and persistent. Each of the four articles on which I was asked to comment adds to the discussion and merits more detailed praise and criticism than I will give here.

The Kenneth E. Marks et al. study is among the better statistical analyses I have seen on the topic of journal pricesfar superior, for example, to the Association of Research Libraries effort. There are still missing elements, however, with circulation (number of copies sold) being perhaps the most obvious. Circulation data are admittedly hard to acquire, but they are significant for the time period involved. The Marks study started with 1967 , virtually the peak period of library funding. In the 1960s, not only did individual university libraries have funds to support multiple subscriptions, but whole new campuses were being added to state systems, only to be trimmed back in the 1980s. Many of the largest (and most expensive) European science journals saw their subscriptions drop more than 50 percent between 1967 and 1987. Commercial journals from U.S. publishers undoubtedly experienced some decline as well, but often they were starting from a larger base and suffered a smaller percentage decrease. Prices have been adjusted consistently to compensate for falling subscriptions.

Regardless of the reason for price increases, the net result is that libraries are able to own an ever declining percentage of the world's literature. What I find bewildering is that there are relatively few articles on what can be done to improve access to the approximately 75 percent of the literature not owned. Instead, the emphasis is on creating a utopia for the twenty-first century. This is one muchused method of long-range planning: establish goals or targets; devise strategies and tactics to get there; implement on a year-by-year basis. When the dream or goal is to revolutionize an entire communications system, the strategies and tactics must be very, very good or chaos may be the outcome.

Eldred Smith suggests as a remedy that research librarians run what would be essentially an electronic national periodical center. His economics are faulty, however, based in part on a misunderstanding of all (not just commercial) publishers' cost and revenue sources, and this analysis leads to a barter or shareware concept where there would be no charge for most material. Many of his other assumptions seem equally unlikely, including the notion of large-scale interuniversity cooperation. Slightly tongue-in-cheek, I have suggested in the past that if the United States wanted to be more efficient with its tax dollars, it should merge the continental forty-eight states into a maximum of sixteen new states and rationalize duplication in university programs and network development in all institutions-public and private-within those new superstates. Well, that is clearly a politically naive notion, too, but not much more so than the process Smith suggests. Smith is right in emphasizing that these changes will take decades to occur.

Paul Metz and Paul M. Gherman provide a thoughtful analysis of the present serials situation, although I could nitpick on details, particularly the notion of copyright impeding access to ideas. Copyright, as Ann Okerson rightly distinguishes in her article, does not inhibit or limit the flow of ideas, only the copying and distribution of specific expressions of the ideas. As someone who has twice experienced others reproducing her works verbatim and without attribution-that is, presenting them as their own-I do not take copyright lightly. Most of us have little to represent ourselves besides our words, and our effort

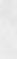


in putting those words together deserves some protection.

Metz and Gherman propose electronic journals (e-journals) as the solution to the journal cost problem, and over the long term (again, decades), they may well be right. E-journal use shifts much of the distribution cost and effort to the reader (or a library or another intermediary). At a minimum one usually will want to download and print out lengthy material for off-screen study. Based on the limited sample of the one electronic newsletter that I receive, this is a tedious and unsatisfactory process and one that I would be loathe to have to rely on as my main data-gathering mode. But it surely will get easier, and the quality of layout and reproduction will improve, so the options should be pursued by all, including universities and commercial publishers.

Okerson delivers a similar message: university-based control over scholarly publications and distribution electronically. The underlying hope or premise is that the university has a higher standard of morality and altruism than does business. Although I have worked in both environments, the truth of this premise is not immediately obvious to me. It is an intriguing notion and one that should perhaps be the subject of a separate article or discussion.

The Smith, Metz and Gherman, and Okerson articles have in common the sense that the current system is broken beyond repair and radical redefinition is the answer. The redefinition centers around universities or librarians taking control of the publication process via electronic media and acknowledges that this is a long process of at least a decade, perhaps two. But what happens in the meantime? How can access be improved to the 75 percent of the literature not owned? What would happen if publishers or others created the electronic archives now, along with the electronic tools to make it easy for scholars to access these archives directly over the network, without reference to the library at all? In fact (of course) that is precisely what is happening and where the major pressure is being felt by publishers, as commercial services (including offshoots of library consortia) seek to license journal material for electronic storage and document delivery. Few librarians (or publishers) seem to have analyzed what these services-fast, efficient, and networkbased-will mean for collection development or subscription sales. Yet the decisions that will be made on these services over the next two to three years may do more to change the economics of journals and journal access than all of the talk of e-journals and university-owned publishing. It is harder to talk about what we can really do today, but I suggest we try to shift to that subject.-Karen Hunter

\section{SERVING THE NEEDS OF SCHOLARLY PRESERVATION AND DISSEMINATION: FOCUS ON THE CUSTOMER}

The editor's note to each article in College \& Research Libraries' series on serials pricing informs us that the series deals with "scholarly communications and serials prices." As a reviewer who is not a regular consumer of CERL, I became somewhat cynical about the issue as I read the abstract and opening page of Eldred Smith's contribution. From his plaintive introduction, I learned that the research librarian's lot is a mighty hapless one-a task faced with "crisis," a "dilemma" that is "an increasingly intolerable burden," the latest episode in a "continuing historic," "heroic," and "losing struggle." Yet I also recognized that the problems he cited are real, and in their efforts to suggest solutions to the crisis, all the authors in this series indirectly reflect the goals that, I suspect, dominate the plans of many research libraries. Consider the following:

Goal: To develop solutions to control, reduce, and stabilize the costs of serials publications.

Goal: To facilitate changes in federal copyright laws.

Goal: To encourage the university to change the academic reward structure.

Goal: To promote greater utilization of electronic information and technology. 
Such goals are not frivolous, yet, I wonder whether they are sufficiently fundamental.

Smith observes that most of the suggestions for dealing with expanding prices and proliferating publications typically promise only short-term adjustments, providing a temporary equilibrium that fails to provide long-term solutions. The source of more lasting solutions may be found in the mission of the research library. But is it the business of these libraries to provide the greatest number of titles at the least cost? Or is it their mission to acquire and disseminate the record of scholarship? If the answer is closer to the second question than the first, then greater attention needs to be given to the scholar as both purveyor and consumer of scholarship. In the following paragraphs, I will comment briefly on the view of the customer as the focal point for addressing the issue, on the need for better data on which to make decisions, on avoiding blame in the search for solutions, and on the limitations of some of the solutions being proffered.

\section{Focusing on the Customer}

C\&RL's series on scholarly communications and serials pricing identifies and discusses to varying degrees the role of the librarian, university, scholar, research funder, and publisher. Each has needs that, in turn, must be served by the others. However, if we are to address these multiple needs, we must begin with the needs of the scholar as the primary customer. What information does the scholar need? How quickly? How often? In what form? What is the best means by which to communicate her or his scholarly ideas, research activities, and results? How do these needs differ from wants, which cannot and should not always be met? Much of what we know about the answers to such questions is based on assumptions and anecdotes. What data do we have to support these assumptions?

\section{Data for Decision Making}

The premise for the study conducted by Kenneth E. Marks et al. was to pro- vide better price information for decision making. If changes are going to be made in the processes that serve the mission of collecting and disseminating scholarship, more information about the processes themselves needs to be collected and collected continuously. A vast array of processes is involved, including scholarship itself, editing, publishing, acquisition, distribution, funding, and the scholarly reward system.

\section{Avoiding Blame}

Focusing on collecting and analyzing data about processes also averts the tendency to assign blame. Smith asks, "Who is to blame?" but goes on to observe that considerable fruitless energy has been expended in directing and assessing blame within the scholarly and publishing communities. Ann Okerson reports that the issue of reproduction and dissemination often pits readers and librarians against publishers. And Paul Metz and Paul M. Gherman write that there has been much "harrumphing" and "finger pointing" among the scholarly societies and commercial publishers regarding willingness to introduce new journals. Seldom, if ever, does attention to determining blame work constructively toward the evolution of a widely acceptable and effective solution.

\section{Limitations}

Among the solutions discussed during this series are the increased use of electronic technology and a return to university-based publishing. Neither automatically ensures cost savings, nor do they guarantee satisfaction of customer needs. Electronic technology raises concerns about interactive software, compatible hardware, and the costs of both; we probably have not as yet discovered the full cost and extent of problems in the physical preservation of scholarship captured in this new form. Similarly, the role of the university as publisher takes on dramatically different characteristics, depending on whether this role is assumed as a means to generate new sources of revenues or whether the university is expected to assume a greater subsidization

.

(1)


of the collection and dissemination of scholarship. Once again, the role of both the electronic technology and the university in addressing the issues of knowledge proliferation, dissemination, and cost can be best determined by focusing on the relevant processes and the needs of the respective customers.

\section{CONCLUSION}

Okerson suggests that the issue at hand is not pricing, but a dysfunctional and endangered scholarly publishing system. The resolution of this broader issue may require, in the words of Metz and Gherman, the forging of a new paradigm, not just for librarians, but for scholarship in general. Yet, Smith asks, is the scholarly community ready to support change in the way in which scholarship is presented and disseminated? Regardless of the magnitude of existing problems, support for a new paradigm is most likely to emerge if it addresses the basic needs of scholars.-G. Gregory Lozier

\section{REFERENCES}

1. Gayle Feldman, "Going Dutch," Publishers Weekly 238(27):19 (June 21, 1991).

2. James J.F. Kels, letter to Elsevier customers dated August 7, 1991.

\section{IN FORTHCOMING ISSUES OF COLLEGE \& RESEARCH LIBRARIES}

Ranking and Evaluating the ARL Library Map Collections Charles A. Seavey

The Evolution of Cooperative Collection Development in Alabama Academic Libraries Sue O. Medina

Are Patrons Ready for "Do-It-Yourself" Services?

Nancy Larsen Helmick

The Academic Library Job Market: A Content Analysis Comparing Public and Technical Services David W. Reser and Anita P. Schuneman

Science Literacy: A Discussion and Information-Based Definition

Gregg Sapp

Academic Library Responses to Journal Price Discrimination

Jean Walstrom Haley and James Talaga

Keyword Searching on an Online Public Access Catalog: Characteristics of Users and Nonusers Pat Ensor 